\title{
The Vacuum-Assisted Closure Device Increases Value in the Treatment of Gustilo Grade IIIb Open Tibia Fractures in Children
}

\author{
Alex Mayers $^{1}$, Mark L. Dunleavy ${ }^{2}$, Michael M. Chau ${ }^{3}$, William Hennrikus ${ }^{2}$ \\ 1. Orthopaedics, Geisinger Medical Center, Danville, USA 2. Orthopaedics, Penn State Health Milton S. Hershey Medical \\ Center, Hershey, USA 3. Orthopaedics, University of Minnesota School of Medicine, Minneapolis, USA
}

Corresponding author: Mark L. Dunleavy, markdun48@gmail.com

\section{Abstract \\ Background}

Wound management associated with Gustilo grade IIIb open tibia fractures in children often requires muscle flaps, skin grafts, and amputations. The purpose of this study is to report the outcomes and complications of vacuum-assisted closure (VAC) treatment, as well as discuss its role in optimizing value when treating these injuries.

\section{Methods}

A retrospective review of medical records and imaging studies was performed from 2008-2015. Six pediatric patients with Gustilo grade IIIb fractures managed with the VAC were identified. The time to treatment, frequency of VAC changes, VAC size, and closure attempts, including muscle flaps and skin grafts, were documented. Fracture fixation methods, the incidence of delayed union or nonunion, as well as the occurrence of deep tissue infection and compartment syndrome were detailed.

\section{Results}

Five patients were male and one was female with an average age of 12 years (range 8-15 years). All patients sustained a Gustilo IIIb open tibia fracture and were treated with irrigation, debridement, intravenous (IV) antibiotics, fixation, and a VAC as a wound care adjunct. Three patients required both a muscle flap and a skin graft. One patient required a skin graft. There was one case of deep tissue infection. Three patients were treated successfully with the VAC alone and did not require any flap procedures.

\section{Conclusions}

Wound care for Gustilo grade IIIb open tibia fractures in children traditionally involved potentially painful twice-daily dressing changes with solutions such as dilute bleach or iodine. The implementation of VAC markedly reduced the frequency of dressing changes every three days. In the current study, the open wound gradually closed with only a VAC in $50 \%$ of Gustilo grade IIIb open pediatric tibia fractures. In summary, the VAC is an adjunct that increases value in the care of pediatric patients with Gustilo grade IIIb open tibia fractures (Value $=$ Outcomes $/$ Cost).

\section{Level of evidence}

Therapeutic level IV

Categories: Pediatrics, Orthopedics, Trauma

Keywords: vacuum-assisted closure, value, open, fracture, pediatric, children

\section{Introduction}

Open tibia fractures in children are rare and account for only $2 \%$ of all pediatric fractures [1]. Approximately $30 \%$ of these are high-energy Gustilo grade III injuries, which can result in infection, compartment syndrome, bone loss, and neurovascular damage [2]. Although the soft tissues in grades I and II fractures can frequently be closed primarily, wound management associated with Gustilo grade IIIb tibia fractures often requires muscle flaps and skin grafts. Delays in coverage of greater than one week have been shown to correlate with worse outcomes [3-4].

Traditionally, twice-daily "wet-to-dry” dressing changes have been employed as a temporary barrier until definitive coverage could be achieved [5-6]. Twice daily dressing changes can cause fear, anxiety, and pain in the pediatric population [7-8]. The vacuum-assisted closure (VAC) device is an alternative and effective method for providing an occlusive dressing, only requiring a change every three days. Prior retrospective data in the pediatric literature supports the use of VAC as a means of reducing infection risk and the need for 
free flaps following open fractures [9-11]. As a result, VAC treatment may play an important role in maximizing health outcomes while reducing spending, thus improving value in the approach to treating severe pediatric open fractures (Value = Outcomes/Cost) [12]. The purpose of this study is to retrospectively examine the outcomes and complications of VAC treatment in a series of grade IIIb open tibia fractures in children and report its role in optimizing value when treating these injuries.

\section{Materials And Methods}

The study was approved by the College of Medicine Institutional Review Board (IRB). A retrospective review of medical records and imaging studies from 2008-2015 was performed. The Gustilo-Anderson classification was used to assess the severity of the open fractures. Type IIIB fractures involve fractures with extensive soft tissue injuries requiring a rotational or free flap for coverage [13-14]. Six pediatric patients with Gustilo grade IIIb fractures managed with a VAC were identified. The time to treatment, frequency of VAC changes, and VAC size, closure attempts, including muscle flaps and skin grafts, were documented. All VAC changes were performed in the OR every three days, which allowed wound inspection and prevented tissue ingrowth into the foam [15]. The VAC suction was set at $-125 \mathrm{mmHg}$ for all patients. Fracture fixation methods, the incidence of delayed union or nonunion, as well as the occurrence of deep tissue infection and compartment syndrome, were detailed. Descriptive statistics (frequencies, percentages, averages) were used to qualitatively analyze the data.

\section{Results}

A retrospective review of medical records and imaging studies was performed from 2008-2015 and six adolescent patients with Gustilo IIIb open tibia fractures were identified. Five patients were male and one was female with an average age of 12 years (range 8-15 years). All patients sustained a Gustilo IIIb open tibia fracture and were treated with irrigation, debridement, IV antibiotics, fixation, and VAC as a wound care adjunct. The average time from injury to arrival in the emergency department was 51 minutes (range 26-83 minutes). The average time to the first dose of antibiotic was 77 minutes (range 50 to 110 minutes). All five patients were treated with a combination of cefazolin and gentamicin per hospital protocol, which is consistent with the antibiotic regimen most commonly employed at academic institutions [16]. The average time to surgery was 218 minutes (range 159-333 minutes). The duration of hospital admission averaged 13.7 days (range 5-24 days). The patient who stayed 24 days had additional comorbidities. The average length of follow up was 114.3 weeks (range 41-294 weeks). The average VAC size was $83.9 \mathrm{~cm}^{2}$ (range $16 \mathrm{~cm}^{2}-200$ $\mathrm{cm}^{2}$ ). The average number of VAC changes in the hospital was 1.7 (range 1-6). The frequency of VAC changes was every three days under general anesthesia. Three patients required both a muscle flap and a skin graft. One patient required a skin graft. This patient's injury resulted in one case of deep tissue infection (16.7\%). Three patients were treated successfully with the VAC alone and did not require any flap procedure (50\%). The wound size for each of these three patients was $16 \mathrm{~cm}^{2}, 16 \mathrm{~cm}^{2}$, and $48 \mathrm{~cm}^{2}$. Two patients required bone grafts. Four fractures were fixed externally while two were fixed with intramedullary flexible nails. Four patients experienced delayed unions ( $>4$ months to heal) - all eventually healed. There was no case of malunion, leg length discrepancy $>1 \mathrm{~cm}$, angulation $>10$ degrees, ROM deficit, amputation, or deep pin tract infection.

Table 1 provides the location of soft tissue defects and the number requiring flaps while Table 2 lists descriptive statistics regarding VAC changes.

\begin{tabular}{|l|l|l|l|}
\hline Location & Proximal $3^{\text {rd }}$ Tibia & Middle $3^{\text {rd }}$ Tibia & Distal $3^{\text {rd }}$ Tibia \\
\hline Number of patients $(\%)$ & 0 & $3(50 \%)$ & $3(50 \%)$ \\
\hline Incidence of flaps & - & 2 & 1 \\
\hline
\end{tabular}

TABLE 1: Location of soft tissue defects and number requiring flaps 


\section{Cureus}

\begin{tabular}{|c|c|c|c|}
\hline & Min & Max & Mean \\
\hline VAC size $\left(\mathrm{cm}^{2}\right)$ & 16 & 200 & 83.9 \\
\hline \#VAC changes in the hospital & 1 & 6 & 1.7 \\
\hline \#VAC changes without anesthesia & 0 & 0 & - \\
\hline Days in hospital & 5 & 24 & 13.7 \\
\hline Time to union (days) & 106 & 928 & 271 \\
\hline Duration of follow up (weeks) & 41 & 294 & 114.3 \\
\hline
\end{tabular}

TABLE 2: Descriptive statistics regarding VAC changes and resultant length of stay and time to union

VAC: vacuum-assisted closure

\section{Discussion}

Gustilo grade IIIb open tibia fractures in children can lead to compartment syndrome, nonunion, and deep infection. The pediatric biology of fracture repair provides advantages over adults, however, including a better periosteal regenerative capacity and soft tissue healing ability [17]. Favorable outcomes can thus be achieved when adhering to evidence-based practices of open fracture management, including immediate IV antibiotics, thorough debridement of contaminated and devitalized tissue, and early fracture stabilization [18]. The management of soft tissue defects is evolving. The current trend is to expedite the timing to definitive closure to reduce infection rates [3-4]. Multiple recent studies have demonstrated the safety of early primary closure in grade I open pediatric both bone forearm fractures [18-19]. In the adult literature, early primary closure in Gustilo grades I, II, and IIIA open fractures has been associated with comparable rates of infection and nonunion as delayed closure [19-20]. For grades IIIB and IIIC injuries, Gopal et al. popularized the "fix and flap" technique in adults, which is a combined ortho-plastic collaborative effort to provide as early internal fixation and flap coverage as possible [21]. Nandra et al. advocated a similar technique in the pediatric population [16]. An effective means of temporary coverage is necessary to prevent infection and maintain the integrity of the soft tissues.

Since the 1990s, VAC has been a valuable adjunct to treating complex wounds as both an occlusive dressing and a wound closure device [22-23]. In a recent retrospective review of pediatric open tibia fractures treated with VAC, Dedmond et al. demonstrated a 50\% decrease in the use of free tissue transfers or rotational muscle flaps for coverage [10]. Similarly, Shilt et al. retrospectively reviewed 31 pediatric lawnmower injuries comparing VAC and traditional wound management techniques, finding a $30 \%$ reduction in the necessity of flaps [11]. In three of the six cases (50\%) in the current study, the open wound gradually closed with VAC, obviating the need for a muscle flap procedure. When examining the distal third tibia shaft fractures specifically, only one of three cases (33\%) required a free flap following VAC treatment, which is notable, as this is traditionally an area where flaps are required for coverage.

Multiple studies have shown a decreased bacterial load in wounds treated with VAC as compared to traditional "wet-to-dry" dressings [6,24-26]. Halvorson et al. reported a 5\% overall infection rate in open pediatric fractures treated with a VAC, much lower than historical controls [9]. In the current study, only one patient $(16.7 \%)$ developed a deep infection. This infection was successfully treated with seven days of IV vancomycin and three days of oral trimethoprim-sulfamethoxazole.

According to Porter, value in healthcare is defined as health outcomes per cost. Achieving high value for each patient is a priority of the healthcare system [12]. The use of VAC increases value in the treatment of Gustilo grade IIIb open tibia fractures in children for multiple reasons. The use of VAC reduces the necessity for and/or the size of flaps procedures compared to traditional wound care approaches. The estimated daily cost of commercially available VAC treatment is roughly between $\$ 100$ and $\$ 450$ (cost $\$ 436$ at our institution). This cost can be reduced by using locally developed systems in resource-depleted third world countries [15,27]. In comparison, the cost of rotational and free flaps is estimated to be up to $\$ 12,000$ and $\$ 20,000$, respectively [28]. Additionally, VAC treatment has been associated with reduced bacterial loads and lower rates of infection in open fractures. The hospital-related cost of an infected tibia fracture is 6.5 times higher than an uninfected case. Sixty-two percent (62\%) of this increased cost is related to longer hospital stays [29]. Thus, the reduction in both the need for free flaps and infection rates can reduce costs and lead to an increase in value.

This study has limitations including the retrospective design and small study population from a single 
center. Additionally, there was no comparison group to act as a control. Future areas of research should prospectively investigate the utilization of VAC to increase value in the treatment of open pediatric tibia fractures, perhaps by including it as a component of a standardized clinical assessment and management plan (SCAMP) such as the one formulated by Luther et al. to treat pediatric torus fractures [30].

\section{Conclusions}

Gustilo grade IIIb open pediatric tibia fractures are challenging injuries to treat. In our study, VAC increased value by reducing the number and frequency of dressing changes, sedations/anesthetics, flaps, infections, and complications historically seen with high-grade open tibia fractures in children. The utilization of a VAC dressing obviated the need for a flap procedure in $50 \%$ of cases. Complications included one infection and four cases of delayed union (> 4 months), although all fractures ultimately healed.

\section{Additional Information \\ Disclosures}

Human subjects: Consent was obtained by all participants in this study. Animal subjects: All authors have confirmed that this study did not involve animal subjects or tissue. Conflicts of interest: In compliance with the ICMJE uniform disclosure form, all authors declare the following: Payment/services info: All authors have declared that no financial support was received from any organization for the submitted work. Financial relationships: All authors have declared that they have no financial relationships at present or within the previous three years with any organizations that might have an interest in the submitted work. Other relationships: All authors have declared that there are no other relationships or activities that could appear to have influenced the submitted work.

\section{References}

1. Cheng JC, Ng BK, Ying SY, Lam PK: A 10-year study of the changes in the pattern and treatment of 6,493 fractures. J Pediatr Orthop. 1999, 19:344-350. 10.1097/01241398-199905000-00011

2. Gougoulias N, Khanna A, Maffulli N: Open tibial fractures in the paediatric population: a systematic review of the literature. Br Med Bull. 2009, 91:75-85. 10.1093/bmb/ldp019

3. Shapiro J, Akbarnia BA, Hanel DP: Free tissue transfer in children . J Pediatr Orthop. 1989, 9:590-595. 10.1097/01241398-198909010-00016

4. Patzakis MJ, Wilkins J: Factors influencing infection rate in open fracture wounds . Clin Orthop Relat Res. 1989, 36:40. 10.1097/00003086-198906000-00006

5. Prokuski L: Negative pressure dressings for open fracture wounds . Iowa Orthop J. 2002, 22:20-24.

6. Stannard JP, Volgas DA, Stewart R, McGwin GJ, Alonso JE: Negative pressure wound therapy after severe open fractures: a prospective randomized study. J Orthop Trauma. 2009, 23:552-557. 10.1097/bot.0b013e3181a2e2b6

7. King A, Stellar JJ, Blevins A, Shah KN: Dressings and products in pediatric wound care. Adv Wound Care. 2014, 3:324-334. 10.1089/wound.2013.0477

8. Kroening L, Davids JR: Management of lower extremity riding lawn mower injuries in children . Orthop Nurs. 2000, 19:29-37. 10.1097/00006416-200019020-00006

9. Halvorson J, Jinnah R, Kulp B, Frino J: Use of vacuum-assisted closure in pediatric open fractures with a focus on the rate of infection. Orthopedics. 2011, 34:256-260. 10.3928/01477447-20110526-15

10. Dedmond BT, Kortesis B, Punger K, et al.: Subatmospheric pressure dressings in the temporary treatment of soft tissue injuries associated with type III open tibial shaft fractures in children. J Pediatr Orthop. 2006, 26:728-732. 10.1097/01.bpo.0000242434.58316.ad

11. Shilt JS, Yoder JS, Manuck TA, Jacks L, Rushing J, Smith BP: Role of vacuum-assisted closure in the treatment of pediatric lawnmower injuries. J Pediatr Orthop. 2004, 24:482-487.

12. Porter ME: What is value in health care?. N Engl J Med. 2010, 363:2477-2481. 10.1056/nejmp1011024

13. Gustilo RB, Anderson JT: Prevention of infection in the treatment of one thousand and twenty-five open fractures of long bones: retrospective and prospective analyses. J Bone Joint Surg Am. 1976, 58:453-458. 10.2106/00004623-197658040-00004

14. Gustilo RB, Mendoza RM, Williams DN: Problems in the management of type III (severe) open fractures: a new classification of type III open fractures. J Trauma. 1984, 24:742-746. 10.1097/00005373-19840800000009

15. Kim JJ, Franczyk M, Gottlieb LJ, Song DH: Cost-effective alternative for negative-pressure wound therapy . Plast Reconstr Surgery Glob Open. 2017, 5:e1211. 10.1097/gox.0000000000001211

16. Lavelle WF, Uhl R, Krieves M, Drvaric DM: Management of open fractures in pediatric patients: current teaching in Accreditation Council for Graduate Medical Education (ACGME) accredited residency programs. J Pediatr Orthop B. 2008, 17:1-6. 10.1097/bpb.0b013e3282f104c4

17. Nandra RS, Wu F, Gaffey A, Bache CE: The management of open tibial fractures in children. A retrospective case series of eight years' experience of 61 cases at a paediatric specialist centre. Bone Joint J. 2017, 99:544553. 10.1302/0301-620x.99b4.37855

18. Pace JL, Kocher MS, Skaggs DL: Evidence-based review: management of open pediatric fractures . J Pediatr Orthop. 2012, 2:123-127. 10.1097/bpo.0b013e318259f326

19. Iobst CA, Spurdle C, Baitner AC, King WF, Tidwell M, Swirsky S: A protocol for the management of pediatric type I open fractures. J Child Orthop. 2014, 8:71-76. 10.1007/s11832-014-0554-7

20. Godfrey J, Choi PD, Shabtai L, et al.: Management of pediatric type I open fractures in the emergency department or operating room: a multicenter perspective. J Pediatr Orthop. 2019, 39:372-376. 10.1097/bpo.0000000000000972 
21. Scharfenberger A V, Alabassi K, Smith S, et al.: Primary wound closure after open fracture: a prospective cohort study examining nonunion and deep infection. J Orthop Trauma. 2017, 31:121-126.

10.1097/bot.0000000000000751

22. Jenkinson RJ, Kiss A, Johnson S, Stephen DJG, Kreder HJ: Delayed wound closure increases deep-infection rate associated with lower-grade open fractures. A propensity-matched cohort study. J Bone Joint Surg Am. 2014, 96:380-386. 10.2106/jbjs.1.00545

23. Gopal S, Majumder S, Batchelor AG, Knight SL, De Boer P, Smith RM: Fix and flap: the radical orthopaedic and plastic treatment of severe open fractures of the tibia. J Bone Joint Surg Br. 2000, 82:959-966. 10.1055/s-0028-1100906

24. Argenta LC, Morykwas MJ: Vacuum-assisted closure: a new method for wound control and treatment: clinical experience. Ann Plast Surg. 1997, 38:563-576. 10.1097/00000637-199706000-00002

25. DeFranzo AJ, Argenta LC, Marks MW, et al.: The use of vacuum-assisted closure therapy for the treatment of lower-extremity wounds with exposed bone. Plast Reconstr Surg. 2001, 108:1184-1191. 10.1097/00006534-200110000-00013

26. Morykwas MJ, Argenta LC, Shelton-Brown EI, McGuirt W: Vacuum-assisted closure: a new method for wound control and treatment: animal studies and basic foundation. Ann Plast Surg. 1997, 38:553-562. 10.1097/00000637-199706000-00001

27. Cocjin HGB, Jingco JKP, Tumaneng FDC, Coruna JMR: Wound-healing following negative-pressure wound therapy with use of a locally developed AquaVac system as compared with the vacuum-assisted closure (VAC) system. J Bone Joint Surg Am. 2019, 101:1990-1998. 10.2106/jbjs.19.00125

28. Thornton BP, Rosenblum WJ, Pu LLQ: Reconstruction of limited soft-tissue defect with open tibial fracture in the distal third of the leg: a cost and outcome study. Ann Plast Surg. 2005, 54:276-280.

29. Metsemakers W-J, Smeets B, Nijs S, Hoekstra H: Infection after fracture fixation of the tibia: analysis of healthcare utilization and related costs. Injury. 2017, 48:1204-1210. 10.1016/j.injury.2017.03.030

30. Luther G, Miller PE, Mahan ST, Waters PM, Bae DS: Decreasing resource utilization using standardized clinical assessment and management plans (SCAMPs). J Pediatr Orthop. 2019, 39:169-174. 10.1097/bpo.0000000000000873 